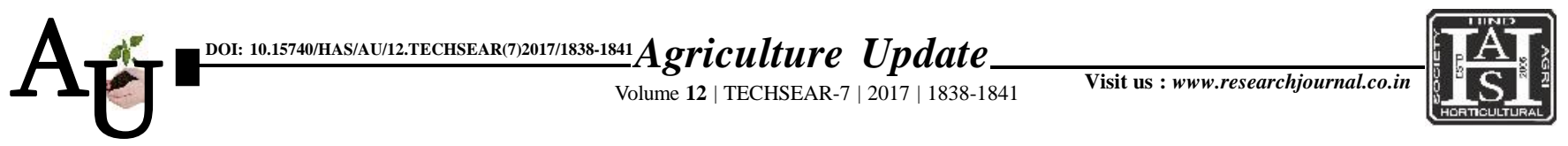

\title{
Research Article: Role of self-help groups in the empowerment of women: A study in Karimnagar district of Telangana sate
}

Article Chronicle : Received : 19.07.2017;

Accepted : 03.08.2017

KeY Words :

Woman empowerment, Self help group,
Author for correspondence :

\section{SHIVAKRISHNA KOTA}

Department of Extension, Agricultural Polytechnic (PJTSAU), Jammikunta, HYDERABAD (TELANGANA) INDIA Email :

kotashivakrishna@ gmail.com

See end of the article for authors' affiliations

\section{SHIVAKRISHNA KOTA, M. SAMPATH KUMAR, VANKUDOTHU RAVINDER NAIK AND B. RAJASHEKAR}

SUMMARY : Self help groups systematically empowering marginalized grass root level women by way of income generation and capacity building. Women empowerment is a process in which women challenge the existing norms and culture, to effectively promote their well being. The participation of women in self-help groups (SHGs) made a significant impact on their empowerment both in social and economical aspects. This study deal with the role of self-help groups in the empowerment of women in Karimnagar district of Telangana State, India. The facts pertaining to the study has been collected from both the primary and secondary data are collected and the age, education, socio-economic variables etc are analysed in demographic information. The study centred on the role of SHGs in women empowerment, social solidarity and socio-economic betterment of the poor for their consolidation.

How to cite this article : Kota, Shivakrishna, Kumar, M. Sampath, Naik, Vankudothu Ravinder and Rajashekar, B. (2017). Role of self-help groups in the empowerment of women: A study in Karimnagar district of Telangana sate. Agric. Update, 12(TECHSEAR-7) : 1838-1841; DOI: 10.15740/HAS/AU/12.TECHSEAR(7)2017/18381841. 